\title{
Can low-grade spondylolisthesis be effectively treated by either coflex interlaminar stabilization or laminectomy and posterior spinal fusion? Two-year clinical and radiographic results from the randomized, prospective, multicenter US investigational device exemption trial
}

\section{Clinical article}

\author{
Reginald Davis, M.D., ${ }^{1}$ Joshua D. Auerbach, M.D., ${ }^{2}$ Hyun Bae, M.D., ${ }^{3}$ and Thomas J. Errico, M.D. ${ }^{4}$ \\ ${ }^{I}$ Greater Baltimore Neurosurgical Associates, Baltimore, Maryland; ${ }^{2}$ Department of Orthopaedics, Bronx-Lebanon \\ Hospital Center, Albert Einstein College of Medicine, Bronx, New York; ${ }^{3}$ The Spine Institute, Santa Monica, California; \\ and ${ }^{4}$ Department of Orthopaedic Surgery, Hospital for Joint Diseases, NYU Langone Medical Center, New York, \\ New York
}

\begin{abstract}
Object. Posterolateral spinal fusion (PSF) has long been the standard of care for degenerative spondylolisthesis, but less invasive, motion-preserving alternatives have been proposed to reduce the complications associated with fusion while still providing neural decompression and stabilization. The object of the current study is to evaluate the safety and efficacy of coflex Interlaminar Stabilization compared with PSF to treat low-grade spondylolisthesis with spinal stenosis.

Methods. This is a prospective, randomized, multicenter FDA investigational device exemption (IDE) trial comparing coflex Interlaminar Stabilization with laminectomy and PSF. A total of 322 patients from 21 sites in the US were enrolled between 2006 and 2008 for the IDE trial. The current study evaluated only the subset of patients from this overall cohort with Grade 1 spondylolisthesis (99 in the coflex group and 51 in the fusion group). Subjects were randomized 2:1 to receive decompression and coflex interlaminar stabilization or decompression and posterolateral spinal fusion with spinal instrumentation. Data collected included perioperative outcomes, Oswestry Disability Index (ODI), back and worse leg visual analog scale (VAS) scores, 12-Item Short Form Health Survey, Zurich Claudication Questionnaire (ZCQ), and radiographic outcomes at a minimum of 2 years. The FDA criteria for overall device success required the following to be met: 15-point reduction in ODI, no reoperations, no major devicerelated complications, and no postoperative epidural injections.

Results. At a minimum of 2 years, patient follow-up was $94.9 \%$ and $94.1 \%$ in the coflex and fusion control groups, respectively. There were no group differences at baseline for any demographic, clinical, or radiographic parameter. The average age was 63 years in the coflex cohort and 65 years in the fusion cohort. Coflex subjects experienced significantly shorter operative times ( $p<0.0001)$, less estimated blood loss $(\mathrm{p}<0.0001)$, and shorter length of stay $(\mathrm{p}<0.0001)$ than fusion controls. Both groups experienced significant improvements from baseline at 2 years in ODI, VAS back, VAS leg, and ZCQ, with no significant group differences, with the exception of significantly greater ZCQ satisfaction with coflex at 2 years. FDA overall success was achieved in $62.8 \%$ of coflex subjects (59 of 94) and 62.5\% of fusion controls (30 of 48) ( $\mathrm{p}=1.000)$. The reoperation rate was higher in the coflex cohort (14 [14.1\%] of 99) compared with fusion $(3[5.9 \%]$ of $51, p=0.18)$, although this difference was not statistically significant. Fusion was associated with significantly greater angulation and translation at the superior and inferior adjacent levels compared with baseline, while coflex showed no significant radiographic changes at the operative or index levels.

Conclusions. Low-grade spondylolisthesis was effectively stabilized by coflex and led to similar clinical outcomes, with improved perioperative outcomes, compared with PSF at 2 years. Reoperation rates, however, were higher in the coflex cohort. Patients in the fusion cohort experienced significantly increased superior and inferior level angulation and translation, while those in the coflex cohort experienced no significant adjacent or index level radiographic changes from baseline. Coflex Interlaminar Stabilization is a less invasive, safe, and equally efficacious clinical solution to PSF to treat low-grade spondylolisthesis, and it appears to reduce stresses at the adjacent levels. Clinical trial registration no.: NCT00534235 (ClinicalTrials.gov). (http://thejns.org/doi/abs/10.3171/2013.4.SPINE12636)
\end{abstract}

KEY WORDS • degenerative spondylolisthesis • coflex • fusion $•$ spinal stenosis

Abbreviations used in this paper: $\mathrm{AE}=$ adverse event; $\mathrm{BMP}=$ bone morphogenetic protein; $\mathrm{CCS}=$ composite clinical success; $\mathrm{CEC}=$ Clinical Events Committee; IDE = investigational device exemption; ODI = Oswestry Disability Index; PSF = posterolateral spinal fusion; SF-12 = 12-Item Short Form Health Survey; SPORT DS = Spine Patient Outcomes Research Trial for degenerative spondylolisthesis; VAS = visual analog scale; ZCQ = Zurich Claudication Questionnaire.
$\mathrm{S}$ INCE the classic article from Herkowitz and Kurz ${ }^{4}$ in 1991 in which fusion significantly outperformed decompression alone in a prospective, randomized controlled trial, lumbar spinal fusion has been the standard

This article contains some figures that are displayed in color online but in black-and-white in the print edition. 


\section{Spondylolisthesis treated with coflex stabilization of fusion}

of care treatment for degenerative spondylolisthesis. ${ }^{18,19}$ While questions remain surrounding the ideal fusion construct to treat degenerative spondylolisthesis, others have challenged that notion and instead have suggested that stabilization - but not necessarily spinal fusion - may be sufficient, and may obviate the well-documented complications that may result following a traditional fusion procedure. ${ }^{9-11,13,16,17,20}$

The coflex Interlaminar Stabilization device (Paradigm Spine) is a single, compressible, metallic U-shaped implant that is inserted into the interlaminar space after a direct microsurgical decompression (that is, laminotomy) to stabilize the motion segment, maintain the direct neurological decompression, and unload the facet joints. The US FDA IDE trial compared coflex Interlaminar Stabilization with PSF in the treatment of patients with the following diagnoses: 1) spinal stenosis with low-back pain (without spondylolisthesis), and 2) degenerative spondylolisthesis. A planned interim analysis was performed when $70 \%$ of patients had achieved a minimum of 2 years of follow-up, the results of which demonstrated equivalence or superiority with coflex compared with PSF in all perioperative and clinical outcomes. ${ }^{1}$ However, it remains unclear if the coflex device is able to provide sufficient stabilization in patients with spondylolisthesis, for whom fusion is typically performed. ${ }^{14}$ The purpose of the current study is to report the comparative effectiveness of coflex Interlaminar Stabilization compared with PSF in the low-grade spondylolisthesis cohort $(n=150)$ from the overall IDE study $(n=$ 322 ) with a minimum of 2 years of follow-up.

\section{Methods}

\section{Study Design}

On April 12, 2006, the US FDA approved commencement of the coflex IDE study, a multicenter, prospective, randomized trial at 21 sites (2:1 investigational device to control randomization) comparing direct decompression with coflex Interlaminar Stabilization with decompression and posterolateral spinal fusion (no interbody cages, no BMP). Patients were enrolled between 2006 and 2008. Investigators and study site personnel were blinded to the randomized treatment option until 5 days prior to surgery, while patients were blinded until after surgery. Randomization was performed within site and number of levels treated based on computer-generated randomization codes. Block size was randomly chosen to be either 3 or 6 . Sixty randomization codes were generated for each study site and level. The study was approved by each of the participating institutional review boards. This clinical trial was registered with ClinicalTrials.gov (trial no. NCT00534235).

\section{Study Conduct}

All clinical data were obtained and managed by an independent contract research organization and were then sent to an independent biostatistician for evaluation. All radiographic data were scanned digitally and sent to an independent core radiographic laboratory (Medical Metrics, Inc.) for evaluation. A CEC, composed of 3 independent board-certified spine surgeons with no affiliation with the study sponsor, reviewed all site-reported AEs and reclas- sified the AE, if necessary, according to 1) AE severity, 2) relatedness of the $\mathrm{AE}$ to the device, and 3) relatedness of the AE to surgery. The CEC adjudications were performed blindly to treatment received, wherever possible. All AEs were graded according to the level of severity as mild, moderate, or severe. A device safety monitoring board met regularly to evaluate and address any potential ongoing safety concerns. All CEC adjudications were binding to the study sponsor.

A total of 322 patients were randomized, with the first 40 coflex patients enrolled being considered "roll-in" or learning curve patients who were not included in the final evaluable cohort. Prior to performing the index coflex procedure, surgeons performed cadaveric implantations and received tutorials on surgical technique and device implantation. A planned interim analysis, performed on the first $70 \%$ of patients who met the minimum 2-year time point for the stenosis (without slip) and degenerative spondylolisthesis populations, has been previously reported. ${ }^{1}$ The current study includes the entire cohort of patients with a minimum 2-year follow-up, with a diagnosis of spondylolisthesis $(\mathrm{n}=150)$.

\section{Patient Population}

In the current study, we report the minimum 2-year results from the entire spondylolisthesis subset $(n=150)$ of patients from the overall IDE trial $(n=322)$ comparing coflex with PSF to treat spinal stenosis and degenerative spondylolisthesis. In the overall IDE trial, patients were required to meet the following stringent inclusion criteria for study enrollment: 1) moderate spinal stenosis with low-back pain, and 2) up to Meyerding Grade 1 (that is, s $25 \%$ sagittal plane translation on flexion-extension radiographs) spondylolisthesis. ${ }^{15}$ Patients with stenosis required a minimum low-back pain component to be eligible for study enrollment, which was assessed by the following: 1) minimum ODI of $20(40 \%)$ of 50 , and 2) VAS back pain $\geq$ $50 / 100$. Other inclusion and exclusion criteria required for enrollment are listed in the Appendix.

\section{Device Description}

The coflex device is an interlaminar stabilization device intended to unload the facet joints, stabilize the motion segment, and maintain the direct neurological decompression. The device is compressible in extension, allows flexion, and is fixed to the laminar bone via a press-fit insertion. It is indicated to treat spinal stenosis with lowback pain and/or Grade 1 Meyerding spondylolisthesis or equivalent retrolisthesis at 1-2 lumbar levels from L1-5. The coflex device is made of titanium alloy and comes in 5 different sizes ranging from 8 to $16 \mathrm{~mm}$ in height in 2-mm increments. A radiograph of the device, preoperative axial MR image of a typical coflex patient, and imaging of a poor surgical candidate due to excessive facet hypertrophy and foraminal stenosis are provided in Fig. 1.

\section{Surgical Technique}

Coflex Cohort. Following a standard midline incision required for laminotomy, the supraspinous ligament is either resected (then later repaired) or retracted laterally. 


\section{R. Davis et al.}

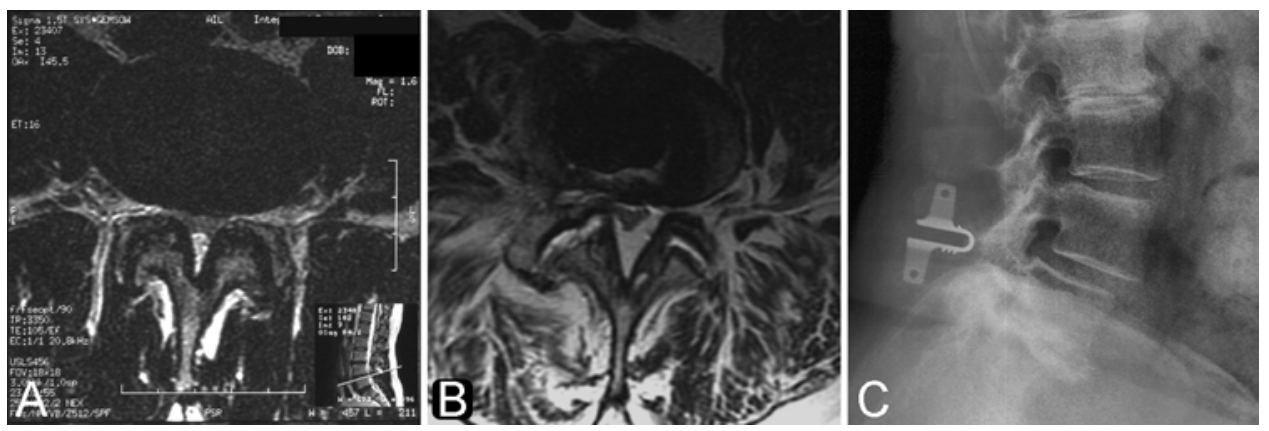

Fig. 1. A: Preoperative axial image obtained in a typical patient suitable for coflex device insertion. B: Preoperative axial image obtained in a patient who would be a poor surgical candidate for coflex due to severe right-sided foraminal stenosis resulting from a Grade 2 spondylolisthesis. C: Implanted L4-5 coflex Interlaminar Stabilization device in a patient with Grade 1 degenerative spondylolisthesis.

This exposes the interspinous space. A high-speed bur or rongeur is then used to remove the minimum amount of spinous process bone required to safely gain access to the interlaminar space and to simultaneously flatten the spinous process and laminar edges so that the coflex device can subsequently be implanted and provide maximum bone-implant interface. A laminotomy is performed in standard fashion, followed by microsurgical decompression so the traversing and exiting neural structures are free of compression. The appropriately sized coflex trial device is then inserted so that a snug fit is achieved. Then, the final device is implanted under fluoroscopic visualization to the level of the facet joints on the lateral intraoperative fluoroscopic imaging. The wings are gently crimped after device placement and confirmation of appropriate positioning. A drain is placed at the discretion of the surgeon, followed by routine closure and postoperative antibiotic prophylaxis.

Fusion Control Cohort. A standard midline incision is made, with dissection out to the tips of the transverse processes. Pedicle screw placement and spinal instrumentation were performed in standard fashion either before or after the laminotomy/decompression at the discretion of the surgeon. Local autograft bone was harvested from the spinous processes and lamina but was not augmented with BMP. Iliac crest bone graft harvesting was not recommended but was performed at the discretion of the surgeon. In total, 29 (56.9\%) of 51 control patients had iliac crest bone graft harvested. The instrumentation systems used were either Expedium (DePuy Spine) or CD Horizon (Medtronic), chosen according to the treating surgeon. No interbody cages were used. A drain was placed at the discretion of the surgeon, and postoperative antibiotics were routinely administered.

\section{Clinical Outcomes Measures}

Clinical outcomes assessments were made at baseline and at each of the following postoperative time points: 6 weeks and 3, 6, 12, 18, and 24 months. Outcomes measures evaluated included ODI, the percentage of patients who improved at least 15 points in the ODI from baseline (ODI-15), SF-12, VAS back and leg scores, and the ZCQ. Overall FDA success criteria required a patient to meet the following 4 end points: 1) improvement of at least 15 points in ODI at 24 months compared with baseline; 2) no reoperations, revisions, removals, or supplemental fixation; 3) no major device-related complications, including but not limited to permanent new or increasing sensory or motor deficit at 24 months; and 4) no lumbar epidural steroid injection at any postoperative time point.

\section{Radiographic Outcomes Measures}

Baseline and 24-month radiographic data are reported for the following outcomes: 1) angulation at the index, superior adjacent, and inferior adjacent levels; and 2) translation at the index, superior adjacent, and inferior adjacent levels. Translation is reported as the percentage of translation in millimeters. Imaging analysis was performed using quantitative motion analysis using upright lateral, anteroposterior, and flexion-extension radiography (Medical Metrics, Inc.). An example demonstrating how adjacentlevel angulation measurements were performed is provided in Fig. 2. Spinal fusion was determined using the following criteria: 1) presence of bridging bone, 2) $3^{\circ}$ or less of angular motion (from flexion to extension), and 3) $3 \mathrm{~mm}$ or less of translational motion (from flexion to extension). All 3 criteria needed to be met for successful fusion.

\section{Statistical Analysis Plan}

This study is a secondary analysis of data from a multisite, randomized clinical trial designed to establish clinical noninferiority of the coflex device relative to control fusion in terms of a Month 24 CCS criterion. The CCS criterion included device survival, pain and function, adverse events, and neurological status, as well as use of a lumbar epidural injection. The Bayesian posterior probability design included an interim analysis when $70 \%$ of a planned 200 coflex and 100 fusion patients reached Month 24 follow-up. The current study restricts attention to all patients determined to have Grade 1 spondylolisthesis $(\mathrm{n}=$ 99 coflex and $\mathrm{n}=51$ fusion). Comparisons include t-tests for comparing group means, computation of standardized effect sizes (mean difference divided by pooled standard deviation) to facilitate interpretability of the relative magnitudes of device differences across end points with varying scales, chi-square and Fisher exact tests to compare categorical outcomes, graphic analyses, and correlational analyses. 

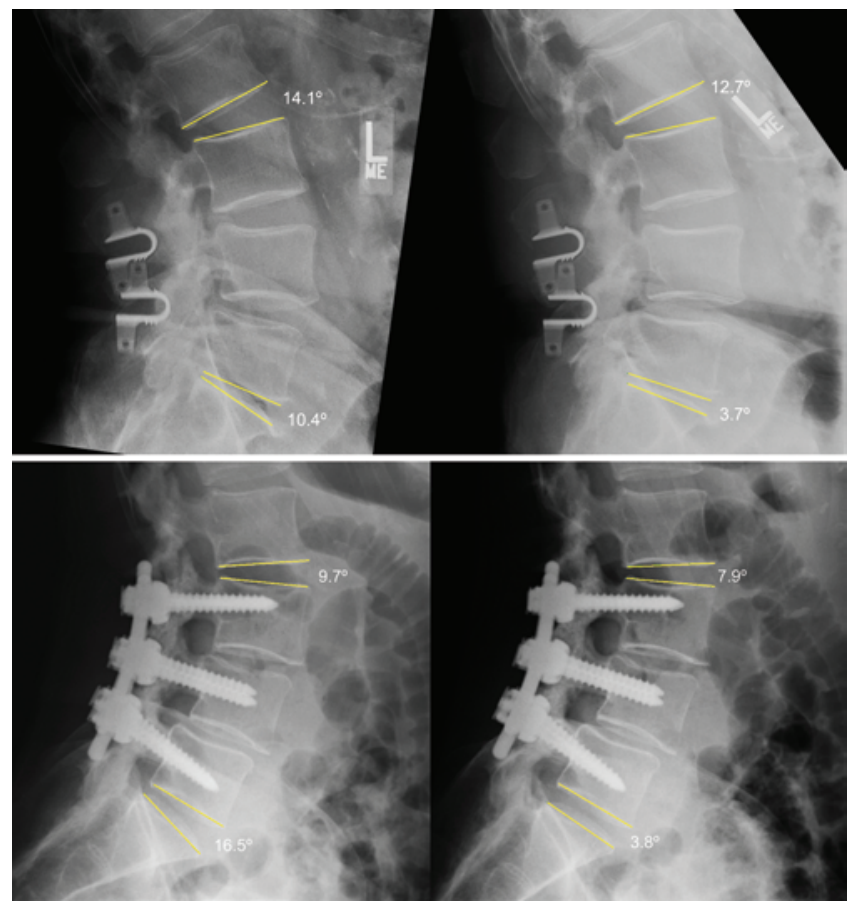

FIG. 2. Dynamic flexion-extension radiographs using the quantitative motion analysis stabilization method to measure angulation at the adjacent levels in a typical 2-level coflex subject (upper) and a typical fusion control subject (lower).

\section{Results}

\section{Patient Follow-Up}

The 24-month follow-up rate was $94.9 \%$ for coflex compared with $94.1 \%$ for fusion controls. The withinwindow follow-up rate for the coflex cohort was $88.8 \%$ and $86.3 \%$ for the fusion group. Figure 3 shows the flow diagram depicting patient enrollment for the overall IDE study and the current study including only patients with spondylolisthesis.

\section{Baseline Demographic Data}

The mean ages of the coflex and fusion cohorts were $63.1 \pm 7.9$ years and $65.0 \pm 8.5$ years, respectively. In the coflex cohort, there were 58 women and 41 men compared with 32 women and 19 men in the fusion cohort. A similar proportion of coflex and fusion subjects underwent 2-level procedures $(64.2 \%$ vs $63.6 \%, \mathrm{p}=1.0)$. There were no significant differences at baseline with respect to age at surgery, height, weight, body mass index, percentage of smokers, or any clinical outcomes measures (that is, ODI, VAS back and VAS leg, SF-12, and ZCQ). The average percentage of slippage at baseline in the coflex and fusion control cohorts was identical at 9.2\% $(\mathrm{p}=0.999)$.

\section{Perioperative Outcomes}

The average operative time for the coflex procedure was 104.1 minutes compared with 157.4 minutes for fusions $(\mathrm{p}=0.000)$. The estimated blood loss was significantly lower with coflex compared with fusion (106.2 vs 335.5 $\mathrm{ml}, \mathrm{p}=0.000)$, and the hospital length of stay was reduced by 1 day (1.95 vs 2.98 days, $\mathrm{p}=0.000)$.

\section{Clinical Outcomes}

The ODIs were similar at baseline and at 2 years postoperatively, at which point the coflex cohort had an average score of 21.1 compared with 22.7 for fusions ( $p=$ 0.66) (Table 1). The percentage of patients that achieved a 15-point reduction in ODI at 2 years from baseline was $86.1 \%$ for coflex and $81.0 \%$ for fusion $(p=0.60)$. With respect to ZCQ outcomes, both groups improved similarly from baseline in physical function and symptom severity scores, but the coflex cohort performed significantly better than fusion controls with respect to ZCQ patient satisfaction at 24 months $(\mathrm{p}=0.05)$ (Table 2). The SF-12 scores were similar at baseline and at 24 months, with no significant differences at any pre- or postoperative time point (Table 3). Table 4 depicts VAS back and (worse) leg pain, with no significant differences noted at baseline or at 24 months. On average, coflex subjects experienced a 55-point improvement in the back VAS score compared with 58 points for fusions $(\mathrm{p}>0.05)$ at 24 months.

\section{Radiographic Outcomes}

Between-Group Comparisons: Angulation. At the operative level, the coflex cohort had $5.03^{\circ}$ of motion compared with $3.91^{\circ}$ in fusions at baseline $(\mathrm{p}=0.07)$. At 24 months, as expected, patients in the fusion cohort had significantly less angulation $\left(1.64^{\circ}\right)$ compared with the coflex cohort $\left(4.32^{\circ}, \mathrm{p}=0.000\right)$.

At the superior adjacent level, the coflex cohort exhibited $4.38^{\circ}$ of motion compared with $3.37^{\circ}$ in the fusion controls $(p=0.10)$ at baseline. At 24 months, however, the fusion controls had significantly greater angulation $\left(5.42^{\circ}\right)$ compared with coflex subjects $\left(3.49^{\circ}, \mathrm{p}=0.007\right)$.

Inferior adjacent-level motion in the coflex cohort averaged $6.42^{\circ}$ compared with $5.75^{\circ}$ in the fusion cohort ( $p$ $=0.38$ ) at baseline. At 24 months, the coflex and fusion groups experienced slight increases from baseline $\left(7.17^{\circ} \mathrm{vs}\right.$ $7.19^{\circ}, \mathrm{p}=0.99$ ).

Between-Group Comparisons: Translation. At the index level, coflex subjects had an average of $1.12 \mathrm{~mm}$ translation at baseline compared with fusion controls, who had 0.98 $\mathrm{mm}(\mathrm{p}=0.34)$. At 24 months, as expected, a significant reduction was seen in the fusion cohort $(0.39 \mathrm{~mm})$ compared with the coflex cohort $(1.08 \mathrm{~mm}, \mathrm{p}=0.000)$.

At the superior adjacent level, the baseline translation in the coflex cohort was $0.87 \mathrm{~mm}$, compared with $0.64 \mathrm{~mm}$ in the fusion cohort $(\mathrm{p}=0.10)$. At 24 months, the coflex cohort experienced a reduction in superior adjacent level translation to $0.74 \mathrm{~mm}$, compared with the fusion cohort, which experienced an increase to $0.97 \mathrm{~mm}(\mathrm{p}=0.12)$.

At the inferior adjacent level, coflex subjects had an average translation of $0.54 \mathrm{~mm}$ at baseline compared with fusions, which averaged $0.49 \mathrm{~mm}(\mathrm{p}=0.56)$. At 24 months, coflex subjects experienced an average translation of 0.69 $\mathrm{mm}$ compared with 0.80 for fusion controls $(\mathrm{p}=0.41)$.

With respect to translation percentages at the adjacent levels, there were no differences at baseline, but at 24 months the fusion cohort experienced a trend toward greater translation percentage at the superior adjacent level compared with coflex subjects $(p=0.06)$. There were no 


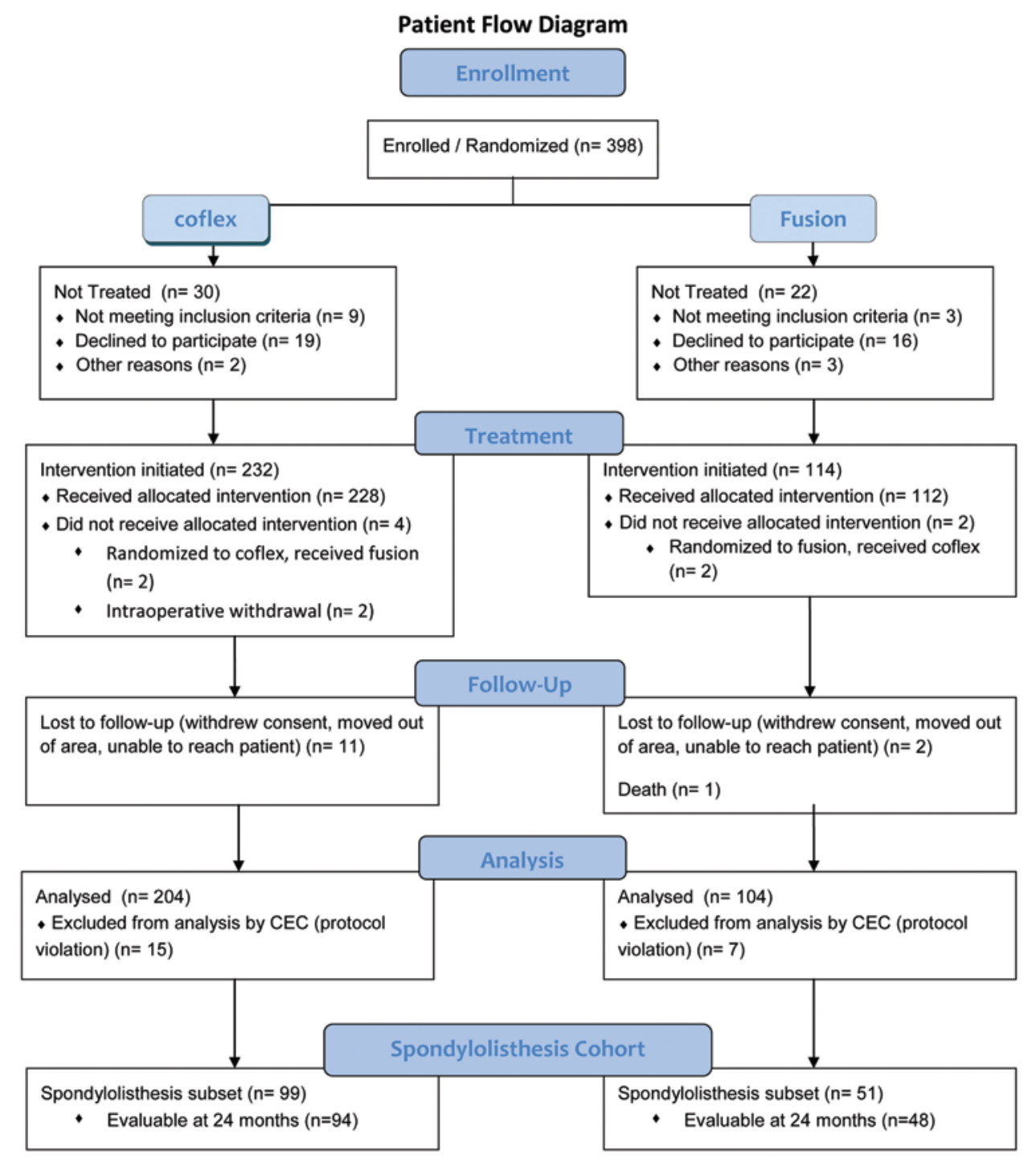

FIG. 3. Patient flow diagram for overall IDE study comparing coflex and fusion cohorts.

differences in translation percentage at the inferior adjacent levels.

Within-Group Comparisons: Angulation. The coflex cohort experienced no significant changes from baseline to 24 months at the operative level $(\mathrm{p}=0.55)$, but the group experienced a trend toward increased angulation at the inferior adjacent level $(p=0.052)$, and no differences from baseline at the superior adjacent level $(p=0.30)$. In contrast, the fusion group experienced a significant reduction in angulation at the index level $(\mathrm{p}=0.000)$, a significant increase at the inferior adjacent level $(\mathrm{p}=0.0026)$, and significant increases from baseline at the superior adjacent level $(\mathrm{p}=0.0013)$.

Within-Group Comparisons: Translation. The coflex cohort exhibited no significant changes from baseline to 24 months at the operative level with respect to translation ( $\mathrm{p}$ $=0.21$ ), but it showed a trend toward increased translation at the inferior adjacent level $(p=0.068)$ and no differences from baseline at the superior adjacent level $(p=0.65)$. In the coflex group there were no differences in translation percentage at the index level $(p=0.93)$, a trend toward increased translation percentage at the inferior adjacent level $(\mathrm{p}=0.06)$, and no differences at the superior adjacent level $(\mathrm{p}=0.55)$.

In contrast, the fusion group experienced a significant reduction in translation at the index level $(\mathrm{p}=0.000)$, a significant increase at the inferior adjacent level $(\mathrm{p}=0.010)$, and a significant increase from baseline at the superior adjacent level $(p=0.0019)$. Similarly, the translation percentage was significantly decreased from baseline to 24 months in the fusion controls at the index level $(\mathrm{p}=0.000)$, significantly increased at the inferior adjacent level $(\mathrm{p}=$ 0.0048 ), and significantly increased at the superior adjacent level $(\mathrm{p}=0.0005)$.

Radiographic Fusion Rate: Fusion Control Cohort. The rate of successful fusion, as assessed using previously established stringent radiographic criteria, was $71 \%$ (36 of $51)$, with similar fusion rates in 1-level cases (27 [71\%] of 
Spondylolisthesis treated with coflex stabilization of fusion

TABLE 1: Descriptive statistics for ODI

\begin{tabular}{|c|c|c|c|c|c|c|c|c|c|}
\hline \multirow[b]{3}{*}{ Time Point } & \multicolumn{6}{|c|}{ Total ODI Score } & \multirow[b]{3}{*}{ p Value* } & \multirow[b]{3}{*}{$\mathrm{p}$ Value $\dagger$} & \multirow{3}{*}{$\begin{array}{l}\text { Effect } \\
\text { Sizeł }\end{array}$} \\
\hline & \multicolumn{3}{|c|}{ Coflex } & \multicolumn{3}{|c|}{ Fusion Control } & & & \\
\hline & No. of Patients & Mean \pm SD & Median (range) & No. of Patients & Mean \pm SD & Median (range) & & & \\
\hline preop & 99 & $59.4 \pm 11.1$ & $58.0(38.0-86.0)$ & 51 & $59.8 \pm 11.5$ & $60.0(40.0-82.0)$ & 0.829 & 0.757 & -0.04 \\
\hline Month 24 & 72 & $21.1 \pm 17.1$ & $18.0(0.0-64.0)$ & 42 & $22.7 \pm 21.0$ & $16.0(0.0-68.0)$ & 0.658 & 0.883 & -0.09 \\
\hline
\end{tabular}

* Two-sample pooled t-test.

$\dagger$ Two-sample Wilcoxon rank-sum test.

‡ Standardized effect size (group difference in means divided by pooled within group SD). Smaller values of the ODI reflect less disability. Therefore, negative effect sizes reflect less disability in the group implanted with the investigational device relative to control.

38) and 2-level fusion cases (9 [69\%] of 13). The rate of fusion in patients with iliac crest bone graft (20 [69\%] of 29) was similar to local autograft only (16 [73\%] of 22, p $=1.00)$.

\section{Overall Success (Primary End Point)}

Overall clinical success was defined as meeting the following composite criteria: 1) improvement of at least 15 points in ODI at 24 months compared with baseline; 2) no reoperations, revisions, removals, or supplemental fixation; 3) no major device-related complications, including but not limited to permanent new or increasing sensory or motor deficit at 24 months; and 4) no lumbar epidural steroid injection at any postoperative time point.

The overall clinical results for primary end point success demonstrates that $59(62.8 \%)$ of 94 coflex subjects and $30(62.5 \%)$ of 48 fusion controls met the criteria for overall study success $(\mathrm{p}=1.000)$.

\section{Overall Complications}

The overall rate of operative site AEs between the groups was similar for coflex (43.4\%) and fusions (37.3\%, $\mathrm{p}=0.49)$. The rate of severe adverse events that were definitely or probably related to the implant was $9.1 \%$ in the coflex group and $7.8 \%$ in the fusion group $(\mathrm{p}=1.0)$. Wound-related problems were seen in $14.1 \%$ of coflex patients compared with $13.7 \%$ in the fusion controls $(\mathrm{p}=1.0)$. The rate of spinous process fracture in the coflex cohort was $18 \%$ (18 of 99); however, by 24 months 7 of these 18 fractures had healed. The CCS for patients experiencing a spinous process fracture was $61.1 \%$ (11 of 18), compared with $63.2 \%$ (48 of $76, p=1.00$ ) in the cohort without a fracture, indicating that these events were mostly asymptomatic findings that did not impact the ultimate clinical outcome. A total of $6.4 \%$ of coflex subjects experienced device movement greater than $5 \mathrm{~mm}$ at 24 months. Woundrelated problems included wound drainage, superficial infection, dehiscence, seroma, and delayed healing of incision. Only 1 patient had an irrigation and debridement procedure due to wound dehiscence. Within the fusion control group, a total of 29\% (15 of 51) developed a pseudarthrosis. There were no differences, however, in clinical outcomes in the pseudarthrosis cohort compared with controls who achieved a solid fusion with respect to ODI and VAS outcomes measures (Table 5).

\section{Reoperations}

The overall reoperation rate was $14.1 \%$ (14 of 99) and $5.9 \%$ (3 of 51) for the coflex and fusion controls, respectively $(\mathrm{p}=0.18)$. The timing and description of reoperations is described in Table 6.

\section{Discussion}

Failure to provide stabilization after laminectomy for

TABLE 2: Descriptive statistics for the ZCQ

\begin{tabular}{|c|c|c|c|c|c|c|c|c|c|}
\hline \multirow[b]{2}{*}{ Score } & \multicolumn{3}{|c|}{ Coflex } & \multicolumn{3}{|c|}{ Fusion Control } & \multirow[b]{2}{*}{ p Value* } & \multirow[b]{2}{*}{$\mathrm{p}$ Value } & \multirow[b]{2}{*}{ Effect Sizeł } \\
\hline & $\begin{array}{l}\text { No. of } \\
\text { Patients }\end{array}$ & Mean \pm SD & Median (range) & $\begin{array}{c}\text { No. of } \\
\text { Patients }\end{array}$ & Mean \pm SD & Median (range) & & & \\
\hline \multicolumn{10}{|c|}{ symptom severity } \\
\hline preop & 98 & $3.54 \pm 0.63$ & $3.57(2.3-5.0)$ & 51 & $3.54 \pm 0.56$ & $3.43(2.6-5.0)$ & 0.987 & 0.895 & 0.00 \\
\hline Month 24 & 72 & $1.90 \pm 0.70$ & $1.79(1.0-3.4)$ & 42 & $2.14 \pm 1.00$ & $2.00(1.0-4.7)$ & 0.144 & 0.421 & -0.28 \\
\hline \multicolumn{10}{|c|}{ physical function } \\
\hline preop & 98 & $2.79 \pm 0.45$ & $2.80(1.6-3.8)$ & 51 & $2.76 \pm 0.47$ & $2.80(1.8-3.6)$ & 0.637 & 0.685 & 0.08 \\
\hline Month 24 & 72 & $1.55 \pm 0.60$ & $1.40(1.0-3.2)$ & 42 & $1.66 \pm 0.69$ & $1.50(1.0-3.8)$ & 0.352 & 0.399 & -0.18 \\
\hline
\end{tabular}

* Two-sample pooled t-test.

$\dagger$ Two-sample Wilcoxon rank-sum test.

‡ Standardized effect size (group difference in means divided by pooled within group SD). Smaller values in the symptom severity and physical function scores reflect greater health-related quality of life. Therefore, negative effect sizes reflect improved health-related quality of life for subjects implanted with the investigational device relative to control. 
TABLE 3: Descriptive statistics for the SF-12 physical and mental component summary scores*

\begin{tabular}{|c|c|c|c|c|c|c|c|c|c|}
\hline \multirow[b]{2}{*}{ Score } & \multicolumn{3}{|c|}{ Coflex } & \multicolumn{3}{|c|}{ Fusion Control } & \multirow[b]{2}{*}{$\mathrm{p}$ Value $†$} & \multirow[b]{2}{*}{ p Valuef } & \multirow[b]{2}{*}{ Effect Size§ } \\
\hline & $\begin{array}{c}\text { No. of } \\
\text { Patients }\end{array}$ & Mean \pm SD & Median (range) & $\begin{array}{l}\text { No. of } \\
\text { Patients }\end{array}$ & Mean \pm SD & Median (range) & & & \\
\hline \multicolumn{10}{|l|}{ PCS score } \\
\hline preop & 89 & $27.7 \pm 6.1$ & $27.3(16.2-46.8)$ & 44 & $28.5 \pm 6.1$ & $28.1(18.0-47.5)$ & 0.485 & 0.338 & -0.13 \\
\hline Month 24 & 69 & $44.1 \pm 10.5$ & $45.1(16.1-59.8)$ & 40 & $43.3 \pm 11.2$ & $42.8(20.5-59.5)$ & 0.722 & 0.880 & 0.07 \\
\hline \multicolumn{10}{|c|}{ MCS score } \\
\hline preop & 89 & $47.0 \pm 12.8$ & 47.3 (18.9-69.1) & 44 & $46.4 \pm 11.9$ & $45.9(19.0-64.0)$ & 0.792 & 0.791 & 0.05 \\
\hline Month 24 & 69 & $54.3 \pm 9.6$ & $57.9(27.4-67.1)$ & 40 & $52.1 \pm 11.3$ & $56.6(23.9-67.2)$ & 0.288 & 0.317 & 0.21 \\
\hline
\end{tabular}

* MCS = mental component summary; PCS = physical component summary.

$\dagger$ Two-sample pooled t-test.

$\ddagger$ Two-sample Wilcoxon rank-sum test.

$\S$ Standardized effect size (group difference in means divided by pooled within group SD). Larger values of the PCS and MCS reflect greater healthrelated quality of life. Therefore, positive effect sizes reflect improvements in the group implanted with the investigational device relative to control.

degenerative spondylolisthesis has been shown to lead to progression of instability, persistent or worsening back pain, and leg pain from recurrent stenosis. ${ }^{4,67,12}$ Consequently, lumbar spinal fusion has been the standard of treatment for this condition, despite the known consequences after fusion including adjacent-segment degeneration, pseudarthrosis, instrumentation problems, donor graft site morbidity, painful hardware, and perioperative morbidity., 4,18 An effective form of motion-preserving stabilization, which still enables direct neural decompression and motion segment stability without the untoward long-term sequelae after lumbar fusion, may facilitate a compromise between the rigidity of fusion and the instability associated with decompression alone in the setting of spondylolisthesis. Our results clearly demonstrate that coflex Interlaminar Stabilization enables the same clinical benefits expected with traditional decompression and lumbar spinal fusion but reduces perioperative morbidity and at 2 years provides evidence of less radiographic adjacent-segment degeneration.

Coflex Interlaminar Stabilization has been performed more than 80,000 times worldwide since its inception by Dr. Jacques Samani in 1994. Although initially developed as a motion-preserving alternative used to treat a variety of lumbar degenerative disorders, long-term clinical data and experience from Europe led to the realization that the subset of patients with spinal stenosis and low-grade spondylolisthesis experienced the most significant improvement. The IDE trial therefore focused on this subset of patients with spinal stenosis and disabling low-back pain, with or without low-grade degenerative spondylolisthesis and compared coflex stabilization with PSF. Although preliminary results from the interim analysis from the overall study cohort (including patients without slippage) revealed that the coflex subjects experienced significant or improved clinical outcomes at 2 years, ${ }^{1}$ questions remained regarding the ability of the coflex device to provide sufficient motion segment stabilization in the setting of spondylolisthesis. ${ }^{14}$

Our results from the current study confirm that coflex interlaminar stabilization is able to adequately stabilize the motion segment and to provide the same clinical outcomes that can be expected from the gold-standard treatment, that is, posterolateral spinal fusion. There were equivalent improvements from baseline in all clinical outcome measures at 2 years. Furthermore, due to the less invasive nature of

TABLE 4: Descriptive statistics for back and maximum leg pain (right and left) VAS scores

\begin{tabular}{|c|c|c|c|c|c|c|c|c|c|}
\hline & \multicolumn{3}{|c|}{ Coflex } & \multicolumn{3}{|c|}{ Fusion Control } & \multirow[b]{2}{*}{ p Value* } & \multirow[b]{2}{*}{$\mathrm{p}$ Value $\dagger$} & \multirow[b]{2}{*}{ Sizeł } \\
\hline & $\begin{array}{c}\text { No. of } \\
\text { Patients }\end{array}$ & Mean \pm SD & Median (range) & $\begin{array}{c}\text { No. of } \\
\text { Patients }\end{array}$ & Mean \pm SD & Median (range) & & & \\
\hline \multicolumn{10}{|l|}{ back pain } \\
\hline preop & 99 & $80.3 \pm 15.2$ & $83.0(29-100)$ & 51 & $78.6 \pm 13.4$ & $83.0(51-100)$ & 0.502 & 0.297 & 0.12 \\
\hline Month 24 & 72 & $25.4 \pm 29.0$ & $11.5(0-100)$ & 42 & $20.6 \pm 26.9$ & $7.0(0-85)$ & 0.380 & 0.292 & 0.17 \\
\hline \multicolumn{10}{|c|}{ leg pain (worse leg) } \\
\hline preop & 99 & $77.9 \pm 19.2$ & $82.0(1-100)$ & 51 & $79.1 \pm 14.9$ & $82.0(38-100)$ & 0.688 & 0.918 & -0.07 \\
\hline Month 24 & 72 & $19.0 \pm 25.0$ & $6.5(0-97)$ & 42 & $22.9 \pm 29.9$ & $5.5(0-95)$ & 0.452 & 0.793 & -0.15 \\
\hline
\end{tabular}

* Two-sample pooled t-test.

$\dagger$ Two-sample Wilcoxon rank-sum test.

‡ Standardized effect size (group difference in means divided by pooled within group SD). The VASs were anchored at 0 (no pain) and 100 (worst possible pain). Therefore, negative effect sizes reflect less pain in the group implanted with the investigational device relative to control. For analysis purposes, leg pain was defined as the maximum pain experienced in the right and left legs. 
Spondylolisthesis treated with coflex stabilization of fusion

TABLE 5: Comparison of clinical outcomes among fusion control subjects who achieved solid fusion versus pseudarthrosis at 2 years*

\begin{tabular}{lccc}
\hline \multicolumn{1}{c}{ Score } & Pseudarthrosis & Solid Fusion & p Value $\dagger$ \\
\hline ODI & & & \\
baseline & 60.1 & 58.9 & 0.738 \\
Month 24 & 20.3 & 24.1 & 0.576 \\
ODI-15 (Month 24) & $12 / 15(80.0 \%)$ & $24 / 29(82.8 \%)$ & $1.000 \ddagger$ \\
VAS & & & \\
back baseline & 79.5 & 77.7 & 0.664 \\
back Month 24 & 16.9 & 26.2 & 0.282 \\
leg baseline & 77.8 & 79.6 & 0.719 \\
leg Month 24 & 20.9 & 24.0 & 0.757 \\
\hline
\end{tabular}

* ODI-15 = improvement of at least 15 points in ODI from baseline.

$\dagger \mathrm{t}$-test unless otherwise indicated.

$\ddagger$ Fisher exact test.

the procedure, the coflex cohort experienced significantly reduced operative times, blood loss, and hospital length of stay. Finally, radiographic evaluation at 2 years indicates that the levels adjacent to the fusion experience significant increases in angulation and translation, both of which are known risk factors for adjacent-segment breakdown. In contrast, the coflex cohort experienced a similar kinematic profile at the index level, in addition to the adjacent levels, at 2 years.

The results from the current study-for both the coflex and fusion cohorts-compare favorably to the 2 year results from the SPORT study as reported by Weinstein et al. ${ }^{18}$ The current cohort of degenerative spondylolisthesis patients in the coflex IDE trial had notably more disability at baseline as assessed by ODI (coflex: 59.4, fusion: 59.8) compared with the baseline ODI from the SPORT DS co- hort (41.8). At 2 years, while the SPORT DS randomized cohort experienced a 24.2-point improvement in ODIs, the coflex cohort in the current study experienced an average ODI improvement of 38.3 points, while fusions improved by 37.1 points. Perioperative outcomes were similarly improved with coflex compared with the PSF controls and the randomized surgically treated degenerative spondylolisthesis cohort in the SPORT study (Table 7). Our results suggest that the coflex cohort performed comparably to the gold standard PSF treatment group not only in the current randomized, prospective trial, but also when compared with other published fusion series in the literature..$^{2-4,10,15,18,19}$

As with any new technology, there are certain complications that are common to all spinal procedures and novel complications that are unique to the technology itself. First, as the coflex device is positioned between 2 contiguous laminae, there is the possibility of a spinous process fracture. Failure to retain at least $14 \mathrm{~mm}$ of spinous process after decompression and spinous process preparation is a risk factor for developing a postoperative spinous process fracture. Patients with osteopenia or osteoporosis are therefore not suitable candidates for interlaminar stabilization because of the theoretical increased risk for spinous process fractures. The presence of a spinous process fracture did not have an untoward effect on clinical outcomes as CCS was equivalent in the fracture and nonfracture groups. Second, coflex patients had a rate of superficial wound infection of $14.1 \%$, compared with $13.7 \%$ for fusion. Although this difference was not statistically significant, the most likely cause is the potential dead space that may be created between the metallic arms of the device. Consequently, we recommend tight fascial closure to minimize this dead space, routine use of a lumbar drain, and postoperative antibiotics. Third, the rate of reoperation was higher in the coflex cohort, although the difference was not statistically significant. The 8 patients who required coflex device removal and conversion to fusion ultimately underwent the

TABLE 6: Reoperation and revision events in the coflex clinical trial: spondylolisthesis cohort

\begin{tabular}{|c|c|c|c|c|c|c|c|c|}
\hline \multirow[b]{2}{*}{ Parameter } & \multirow{2}{*}{$\begin{array}{l}\text { Treatment } \\
\text { Group }\end{array}$} & \multicolumn{5}{|c|}{ Event Time Course (mos) } & \multirow{2}{*}{$\begin{array}{c}\text { Total } \\
\text { (events) }\end{array}$} & \multirow[b]{2}{*}{ Reasons } \\
\hline & & $<1.5$ & $1.5-3$ & $3-6$ & $6-12$ & $12-24$ & & \\
\hline \multicolumn{9}{|l|}{ reop type } \\
\hline irrigation \& debridement & coflex & 2 & 0 & 0 & 0 & 0 & $2 / 99$ & 1 wound dehiscence, 1 wound cellulitis \\
\hline supplemental decompression & coflex & 0 & 0 & 0 & 1 & 0 & $1 / 99$ & 1 leg \&/or low-back pain \\
\hline CSF repair & coflex & 1 & 0 & 0 & 0 & 0 & $1 / 99$ & 1 CSF leak \\
\hline irrigation \& debridement & fusion & 1 & 0 & 0 & 0 & 0 & $1 / 51$ & 1 wound dehiscence \\
\hline \multicolumn{9}{|l|}{ revision type } \\
\hline $\begin{array}{l}\text { device replacement (w/ co- } \\
\text { flex) }\end{array}$ & coflex & 0 & 1 & 0 & 0 & 0 & $1 / 99$ & 1 bone-related fracture \\
\hline $\begin{array}{l}\text { decompression \& device re- } \\
\text { moval }\end{array}$ & coflex & 0 & 0 & 0 & 1 & 0 & $1 / 99$ & 1 leg \&/or low-back pain \\
\hline transition to fusion & coflex & 0 & 0 & 2 & 3 & 3 & $8 / 99$ & $\begin{array}{l}5 \text { leg \&/or low-back pain, } 2 \text { component } \\
\text { loosening, } 1 \text { bone-related fracture* }\end{array}$ \\
\hline $\begin{array}{l}\text { debridement \& device re- } \\
\text { moval }\end{array}$ & coflex & 1 & 0 & 0 & 0 & 0 & $1 / 99$ & 1 deep infection \\
\hline adjacent-level extension & fusion & 0 & 1 & 1 & 0 & 0 & $2 / 51$ & 2 back \&/or leg pain \\
\hline
\end{tabular}

* One patient in the coflex group had a transition to fusion after a previous coflex replacement. 


\section{R. Davis et al.}

TABLE 7: Comparison of coflex IDE perioperative and clinical outcomes to the SPORT DS cohort at 2 years

\begin{tabular}{lccc}
\hline \multicolumn{1}{c}{ Parameter } & Coflex & $\begin{array}{c}\text { PSF } \\
\text { Control }\end{array}$ & $\begin{array}{c}\text { Randomized } \\
\text { SPORT DS Cohort }\end{array}$ \\
\hline op time (mins) & 104 & 157.4 & 210 \\
estimated blood loss (ml) & 106.2 & 335.5 & 570 \\
hospital length of stay (days) & 1.95 & 2.98 & 6.9 \\
$\begin{array}{l}\text { ODI improvement from } \\
\quad \text { baseline to 2 yrs }\end{array}$ & -38.3 & -37.1 & -24.2 \\
overall reop rate at 2 yrs & $10.1 \%$ & $5.9 \%$ & $12 \%$ \\
\hline
\end{tabular}

procedure (primary lumbar fusion) that they would otherwise have received if the coflex device were not available. In other words, in this cohort that ultimately underwent coflex removal and lumbar spinal fusion, the coflex device acted as a bridge between conservative treatment and fusion. In contrast, among the 91 (92\%) of 99 coflex subjects who were not converted to a fusion, coflex interlaminar stabilization provided definitive treatment up to 2 years.

There were several notable study limitations. First, while the majority of patients with degenerative spondylolisthesis are offered arthrodesis or stabilization, it is possible that a subset of patients with a stable slip and with minimal back pain may benefit from decompression only, without the need for stabilization., 5 This group, however, was not the exclusive focus of the current study of patients with mobile slips, and those with severe back pain were also included. Another potential study limitation is the lack of patient blinding to surgical treatment in the postoperative period, which may introduce treatment bias; however, given the inherent group differences in postoperative protocol and incision size, conducting such a study was not feasible. Finally, the current study cannot assess the efficacy of a fusion group consisting of lumbar intervertebral cages or BMP as these components are not on-label in the treatment of degenerative spondylolisthesis with spinal stenosis and therefore were not permitted in the current FDA IDE study.

\section{Conclusions}

Coflex interlaminar stabilization provides equivalent improvements in clinical outcomes when compared with traditional PSF, with distinct improvements in perioperative outcomes and with respect to radiographic risks for adjacent-segment degeneration. After a decompression, the less invasive nature of coflex implantation, which obviates the need for dissection out to the tips of the transverse processes to achieve a posterolateral spinal fusion, requires less operative time, incurs less blood loss, and allows for earlier patient discharge to home. Maintenance of motion at the index level with coflex appears to protect the adjacent levels from increased angulation and translation at 2 years while providing the needed stability at the index level. In contrast, the levels adjacent to fusion-both superior and inferior-exhibited significantly elevated translation and angulation. Longer-term data will be needed to deter- mine whether the radiographic evidence of instability seen at the levels adjacent to fusion will lead to an increased rate of symptomatic involvement of the adjacent levels. The current data support the use of coflex interlaminar stabilization as a motion-preserving alternative to fusion in the treatment of low-grade degenerative spondylolisthesis.

\section{Appendix: Inclusion and exclusion criteria}

\section{Inclusion Criteria}

1. Radiographic confirmation of at least moderate lumbar stenosis, which narrows the central spinal canal at 1 or 2 contiguous levels from L-1 to L-5 that require surgical decompression. Moderate stenosis is defined as $>25 \%$ reduction of the anteroposterior dimension compared with the next adjacent normal level, with nerve root crowding compared with the normal level, as determined by the investigator on CT scanning or MRI. The patient may have, but is not required to have, the following for inclusion in the study:

a. Facet hypertrophy and subarticular recess stenosis at the affected level(s);

b. Foraminal stenosis at the affected level(s);

c. Up to Grade 1 stable degenerative spondylolisthesis (Meyerding classification) or equivalent retrolisthesis as determined by flexion/extension radiography:

i. For single-level disease, there may be up to a Grade 1 stable spondylolisthesis or equivalent retrolisthesis at the affected level as determined on flexion/extension films by the investigator.

ii. For 2-level disease, there may be up to a Grade 1 stable spondylolisthesis or equivalent retrolisthesis at only 1 of the 2 contiguous affected levels as determined on flexion-extension radiographs by the investigator. Patients with up to Grade 1 stable spondylolisthesis at 2 contiguous levels are excluded, but patients with up to Grade 1 stable spondylolisthesis at 1 level and equivalent retrolisthesis at the adjacent level may be included.

d. Mild lumbar scoliosis (Cobb angle up to $25^{\circ}$ ).

2. Radiographic confirmation of the absence of angular or translatory instability of the spine at index or adjacent levels (instability as defined by White and Panjabi: sagittal plane translation > $4.5 \mathrm{~mm}$ or $15 \%$ or sagittal plane rotation $>15^{\circ}$ at L1 $-2, \mathrm{~L} 2-3$, and L3 $-4 ;>20^{\circ}$ at L4-5 based on standing flexion-extension radiographs).

3. Visual analog back pain score of at least $50 \mathrm{~mm}$ on a $100-$ mm scale.

4. Neurogenic claudication as defined by leg/buttocks or groin pain that can be relieved by flexion, such as sitting in a chair.

5. Patient has undergone at least 1 epidural injection at any prior time point and at least 6 months of prior conservative care without adequate and sustained symptom relief.

6. Age between 40 and 80 years.

7. Low-back pain ODI of at least 20 (40\%) of 50.

8. Appropriate candidate for treatment using posterior surgical approach

9. Psychosocially, mentally, and physically able to fully comply with this protocol, including adhering to scheduled visits, treatment plan, completing forms, and other study procedures.

10. Personally signed and dated informed consent document prior to any study-related procedures indicating that the patient has been informed of all pertinent aspects of the trial.

\section{Exclusion Criteria}

More than 2 vertebral levels requiring surgical decompression.

Prior surgical procedure that resulted in translatory instability of the lumbar spine (as defined by White and Panjabi). 


\section{Spondylolisthesis treated with coflex stabilization of fusion} levels.

More than 1 surgical procedure at any combination of lumbar

Prior fusion, implantation of a total disc replacement, complete laminectomy, or implantation of an interspinous process device at any lumbar level.

Radiographically compromised vertebral bodies at any lumbar level(s) caused by current or past trauma or tumor (for example, compression fracture).

Severe facet hypertrophy requiring extensive bone removal that would cause instability.

Isthmic spondylolisthesis or spondylolysis (pars fracture).

Degenerative lumbar scoliosis (Cobb angle $>25^{\circ}$ ). tion.

Disc herniation at any lumbar level requiring surgical interven-

Osteopenia: A screening questionnaire for osteopenia, SCORE (Simple Calculated Osteoporosis Risk Estimation), will be used to screen patients who require a DEXA (dual energy x-ray absorptiometry) bone mineral density measurement. If DEXA is required, exclusion will be defined as a DEXA bone density measured T-score of $\leq-1.0$ (the WHO definition of osteopenia). (Primary location for DEXA scan should be the spine. In the event that the spine T-score is in the osteopenic range [ -1.0 to -2.5$]$, a T-score from the hip may be obtained. If the T-score from the hip comes back above -1.0 then, at the discretion of the investigator, the patient may be considered for inclusion in the study. Also, a hip DEXA may be used in the event that a spine DEXA cannot be obtained.)

Back or leg pain of unknown etiology.

Axial back pain only, with no leg, buttock, or groin pain.

Morbid obesity defined as a body mass index $>40$.

Pregnant or interested in becoming pregnant in the next 3 years.

Known allergy to titanium, titanium alloys, or MRI contrast agents.

Active or chronic infection-systemic or local.

Chronically taking medications or any drug known to potentially interfere with bone/soft-tissue healing (for example, steroids), not including a Medrol dose pack.

History of significant peripheral neuropathy.

Significant peripheral vascular disease (for example, with diminished dorsalis pedis or posterior tibial pulses).

Unremitting back pain in any position.

Uncontrolled diabetes.

Known history of Paget disease, osteomalacia, or any other metabolic bone disease (excluding osteopenia, which is addressed above).

Cauda equina syndrome, defined as neural compression causing neurogenic bowel (rectal incontinence) or bladder (bladder retention or incontinence) dysfunction.

Fixed and complete motor, sensory, or reflex deficit.

Rheumatoid arthritis or other autoimmune disease.

Known or documented history of communicable disease, including AIDS, HIV, and active hepatitis.

Active malignancy: a patient with a history of any invasive malignancy (except nonmelanoma skin cancer), unless he or she has been treated with curative intent and there has been no clinical signs or symptoms of the malignancy for at least 5 years. Patients with a primary bony tumor are excluded as well.

Prisoner or ward of the state.

History of substance abuse (for example, recreational drugs, narcotics, or alcohol).
Currently involved in a study of another investigational product for similar purpose.

Currently seeking or receiving worker's compensation.

In active spinal litigation.

\section{Disclosure}

Dr. Davis is a consultant for and received clinical or research support for this study from Paradigm Spine, LDR, and Zimmer. Dr. Auerbach is a consultant for Paradigm Spine, Synthes Spine, Zyga Technology, Simpirica Spine, Medical Metrics Inc., and Medacta International. Dr Errico received clinical or research support for this study from Paradigm Spine. This study was supported by Paradigm Spine, LLC (New York, NY). The authors are consultants to Paradigm Spine, LLC (New York, NY).

Author contributions to the study and manuscript preparation include the following. Conception and design: Auerbach, Davis, Errico. Acquisition of data: all authors. Analysis and interpretation of data: all authors. Drafting the article: Auerbach. Critically revising the article: Davis, Bae, Errico. Reviewed submitted version of manuscript: all authors. Approved the final version of the manuscript on behalf of all authors: Auerbach.

\section{References}

1. Auerbach JD, Reginald D, Errico T, Bae H: Direct decompression and Coflex interlaminar stabilization compared with laminectomy and posterior spinal fusion with pedicle screw instrumentation for spinal stenosis with back pain or degenerative spondylolisthesis: two-year results from the prospective, randomized, multicenter FDA IDE trial. Spine J 11 Suppl: S86-S87, 2011 (Abstract)

2. Cheng L, Nie L, Zhang L: Posterior lumbar interbody fusion versus posterolateral fusion in spondylolisthesis: a prospective controlled study in the Han nationality. Int Orthop 33: 1043-1047, 2009

3. Fischgrund JS, Mackay M, Herkowitz HN, Brower R, Montgomery DM, Kurz LT: 1997 Volvo Award winner in clinical studies. Degenerative lumbar spondylolisthesis with spinal stenosis: a prospective, randomized study comparing decompressive laminectomy and arthrodesis with and without spinal instrumentation. Spine (Phila Pa 1976) 22:2807-2812, 1997

4. Herkowitz HN, Kurz LT: Degenerative lumbar spondylolisthesis with spinal stenosis. A prospective study comparing decompression with decompression and intertransverse process arthrodesis. J Bone Joint Surg Am 73:802-808, 1991

5. Ikuta K, Tono O, Oga M: Clinical outcome of microendoscopic posterior decompression for spinal stenosis associated with degenerative spondylolisthesis-minimum 2-year outcome of 37 patients. Minim Invasive Neurosurg 51:267-271, 2008

6. Johnsson KE, Redlund-Johnell I, Udén A, Willner S: Preoperative and postoperative instability in lumbar spinal stenosis. Spine (Phila Pa 1976) 14:591-593, 1989

7. Johnsson KE, Willner S, Johnsson K: Postoperative instability after decompression for lumbar spinal stenosis. Spine (Phila Pa 1976) 11:107-110, 1986

8. Kelleher MO, Timlin M, Persaud O, Rampersaud YR: Success and failure of minimally invasive decompression for focal lumbar spinal stenosis in patients with and without deformity. Spine (Phila Pa 1976) 35:E981-E987, 2010

9. Lee SE, Park SB, Jahng TA, Chung CK, Kim HJ: Clinical experience of the dynamic stabilization system for the degenerative spine disease. J Korean Neurosurg Soc 43:221-226, 2008

10. Lee SH, Lee JH, Hong SW, Chung SE, Yoo SH, Lee HY: Spinopelvic alignment after interspinous soft stabilization with a 


\section{R. Davis et al.}

tension band system in grade 1 degenerative lumbar spondylolisthesis. Spine (Phila Pa 1976) 35:E691-E701, 2010

11. Lee SH, Lee JH, Hong SW, Shim CS, Chung See, Yoo SH, et al: Factors affecting clinical outcomes in treating patients with grade 1 degenerative spondylolisthesis using interspinous soft stabilization with a tension band system: a minimum 5-year follow-up. Spine (Phila Pa 1976) 37:563-572, 2012

12. Mardjetko SM, Connolly PJ, Shott S: Degenerative lumbar spondylolisthesis. A meta-analysis of literature 1970-1993. Spine (Phila Pa 1976) 19 (20 Suppl):2256S-2265S, 1994

13. Morishita Y, Ohta H, Naito M, Matsumoto Y, Huang G, Tatsumi M, et al: Kinematic evaluation of the adjacent segments after lumbar instrumented surgery: a comparison between rigid fusion and dynamic non-fusion stabilization. Eur Spine J 20:1480-1485, 2011

14. Park SC, Yoon SH, Hong YP, Kim KJ, Chung SK, Kim HJ: Minimum 2-year follow-up result of degenerative spinal stenosis treated with interspinous U (Coflex). J Korean Neurosurg Soc 46:292-299, 2009

15. Pearson A, Blood E, Lurie J, Tosteson T, Abdu WA, Hillibrand A, et al: Degenerative spondylolisthesis versus spinal stenosis: does a slip matter? Comparison of baseline characteristics and outcomes (SPORT). Spine (Phila Pa 1976) 35:298-305, 2010

16. Schaeren S, Broger I, Jeanneret B: Minimum four-year follow-up of spinal stenosis with degenerative spondylolisthesis treated with decompression and dynamic stabilization. Spine (Phila Pa 1976) 33:E636-E642, 2008
17. Sengupta DK, Herkowitz HN: Degenerative spondylolisthesis: review of current trends and controversies. Spine (Phila Pa 1976) 30 (6 Suppl):S71-S81, 2005

18. Weinstein JN, Lurie JD, Tosteson TD, Hanscom B, Tosteson AN, Blood EA, et al: Surgical versus nonsurgical treatment for lumbar degenerative spondylolisthesis. N Engl J Med 356:2257-2270, 2007

19. Weinstein JN, Lurie JD, Tosteson TD, Zhao W, Blood EA, Tosteson AN, et al: Surgical compared with nonoperative treatment for lumbar degenerative spondylolisthesis. Fouryear results in the Spine Patient Outcomes Research Trial (SPORT) randomized and observational cohorts. J Bone Joint Surg Am 91:1295-1304, 2009

20. Welch WC, Cheng BC, Awad TE, Davis R, Maxwell JH, Delamarter R, et al: Clinical outcomes of the Dynesys dynamic neutralization system: 1-year preliminary results. Neurosurg Focus 22(1):E8, 2007

Manuscript submitted July 10, 2012.

Accepted April 16, 2013.

Please include this information when citing this paper: published online May 31, 2013; DOI: 10.3171/2013.4.SPINE12636. Address correspondence to: Joshua D. Auerbach, M.D., Department of Orthopaedics, Bronx-Lebanon Hospital Center, 1650 Grand Concourse, 7th Floor, Bronx, New York 10457.email: auerspine@ gmail.com. 